\title{
O ensino de ciências nos anos iniciais com o aporte da literatura infantil de Monteiro Lobato
}

Márcia Priscilla Castro Lana marcialana@gmail.com

orcid.org/0000-0001-8327-9147 Universidade Federal de Ouro Preto (UFOP), Ouro Preto, Minas Gerais, Brasil

Fábio Augusto Rodrigues e Silva fabogusto@gmail.com

orcid.org/0000-0003-1245-2648

Universidade Federal de Ouro Preto

(UFOP), Ouro Preto, Minas Gerais, Brasil

\section{RESUMO}

A literatura infantil apresenta um caráter lúdico, atrativo e imaginativo e, por essa razão, é muito usada por professores dos anos iniciais do Ensino Fundamental para auxiliar as crianças a desenvolverem uma maior habilidade no decorrer da aquisição da leitura. Esse suporte pode ser utilizado de maneira ampla e irrestrita em várias situações, como em aulas que tratem de conteúdos relacionados às Ciências Naturais. Este trabalho se propõe a descrever e analisar o processo de ensino e de aprendizagem de Ciências nas séries iniciais do Ensino Fundamental, propiciado por uma atividade que utilizou a literatura infantil para trabalhar conteúdos científicos. Esta pesquisa teve como sujeitos alunos de uma escola pública de uma cidade do interior de Minas Gerais, matriculados no terceiro ano do Ensino Fundamental; efetuou-se a utilização de contos do escritor Monteiro Lobato para o desenvolvimento da atividade. Os turnos de falas foram selecionados a fim de comprovar, por uma análise microgenética, as transformações nas falas que demonstrem a ludicidade, a criatividade e a imaginação mobilizadas pelas histórias e que foram importantes para evidenciar indícios de aprendizagem de ciências. Essa característica de despertar a imaginação própria dos produtos literários é propícia para a aprendizagem da referida disciplina, que, em muitos conteúdos, requer abstração para a compreensão dos fenômenos naturais. Destaca-se que a obra de Monteiro Lobato, utilizada para a atividade, se mostrou uma ferramenta importante, pois se constituiu em um amplificador cultural que permitiu a construção de significados pelas crianças. Essa atividade foi elaborada para os anos iniciais do Ensino Fundamental, mas poderia ser adaptada para outros níveis de ensino.

PALAVRAS-CHAVE: Letramento Científico. Literatura Infantil. Ensino de Ciências. Ensino Fundamental. 


\section{INTRODUÇÃO}

A literatura acompanha a história da humanidade retratando suas lendas, seus mitos e fortalecendo o folclore das populações, enaltecendo e valorizando algumas características que formaram as diferentes gerações. Esse tipo de arte se desenvolveu de uma prática oral até alcançar os dias atuais pelos livros impressos e digitais (COSTA, 2009; GREGORIN FILHO, 2009; ZILBERMAN, 2012).

Alguns desses textos orais que foram transcritos tornaram-se clássicos e, a partir da valorização social da criança, foram adaptados e utilizados para auxiliar na formação de adultos. Esses escritos sofreram, por essa razão, adaptações e acréscimo de linguagem não verbal com a finalidade de estimular a imaginação e a criatividade dos pequenos leitores (ARIÈS, 1981; CADERMATORI, 1991). Em consequência dessa finalidade, os textos adaptados para as crianças foram nomeados de literatura infantil. Muito posteriormente à sua leitura passou a ser associada às atividades pedagógicas, principalmente em Língua Portuguesa, nos processos de alfabetização e letramento (SILVA, 1998).

Alguns autores afirmam que essa ligação entre a literatura infantil com a alfabetização e o letramento não pode ser minimizada a apenas um conteúdo escolar. Eles destacam a importância desse tipo de texto para o aprimoramento da capacidade leitora em todos os assuntos escolarizados, tal como a ciência (ALMEIDA; GIRADELLI, 2008; SABINO, 2008; SILVA, 1998). A literatura infantil pode criar possibilidades para a alfabetização científica por favorecer novas alternativas para o ensino e a aprendizagem de conceitos científicos (ALMEIDA; GIRADELLI, 2008; ANTLOGA; SLONGO, 2012; PIASSI, 2010; SANTOS; SILVA, 1998). Ser uma nova alternativa refere-se ao estímulo do pensamento pela forma como o leitor se relaciona com os textos literários. Tais textos são impregnados de ludicidade, magia e encantamento, auxiliando na abstração que é muitas vezes necessária para o aprendizado de conteúdos científicos (FRANCISCO JÚNIOR; GARCIA JÚNIOR, 2010). O texto literário auxilia nessa alfabetização científica quando fornece um conjunto de conhecimentos que possibilita a aprendizagem (DELIZOICOV; LORENZETTI, 2001) e também quando, ao associar o lúdico e o estímulo à imaginação da literatura infantil, ao ensino de Ciências, medeia de forma diferenciada o contato das crianças com a cultura científica.

Antloga e Slongo (2012) expõem que o lúdico na ciência pode englobar o enredo da história e o aporte das imagens que despertam a fantasia enquanto retratam os fenômenos naturais e os processos tecnológicos. Dessa maneira, a literatura pode fortalecer a compreensão de mundo quando ressignifica o contexto social, sendo um símbolo da sociedade real (BARRONE; PORCACCHIA, 2011). Ao ressignificar o contexto social, a literatura infantil contribui como uma mediadora entre a cultura e o aprendizado, tornando-se um amplificador cultural desse processo (BRASIL, 2007).

Segundo Gerken (2002), o termo amplificador cultural remete à forma pela qual o ser humano é introduzido em um ambiente cultural. $O$ acesso a essa ambiente se faz pelo uso de ferramentas que auxiliam na sua expressão, contribuindo para a aquisição da cultura pelo estímulo psicológico. Tudo o que linguagens oral, gestual e escrita, sendo essa última um amplificador mais 
robusto para o desenvolvimento dos processos mentais superiores. Dell Prette (1995) esclarece que os processos mentais superiores remetem às ações de pensamento, abordado por Vygosty, podendo ocorrer de maneira consciente ou elementar. As ações de pensamento consciente envolvem a solução de problemas e o raciocínio lógico. Já as ações elementares envolvem assimilação, concentração, memória e criatividade.

Dessa forma, a literatura infantil, sendo uma linguagem escrita, pode se constituir em um elemento que atua na aprendizagem, pois auxilia o sujeito na construção de significados. Diante do potencial desse recurso literário, foi proposto um trabalho cujo objetivo é apresentar e analisar o emprego da literatura infantil no processo de ensino e aprendizado de Ciências nas séries iniciais do ensino fundamental I. Busca-se compreender como textos literários podem auxiliar no aprendizado de conceitos científicos. Essa avaliação se deu a partir de dados obtidos em uma aplicação de atividade para alunos do 30 ano de uma escola em uma cidade no interior de Minas Gerais. Essa atividade teve como suporte textos de Monteiro Lobato (2010), que são encontrados no livro "Reforma da Natureza", uma obra que contém diferentes histórias que se voltam para assuntos científicos, mas sem abrir mão do estilo lúdico e fantasioso que permeiam as obras desse autor.

\section{REFERENCIAL TEÓRICO}

A literatura evidencia o pensamento de um povo, seus ideais e sentimentos e se manifesta de maneira oral ou escrita em diversos formatos de texto. Muitas vezes a literatura associa-se à magia e à fantasia (COELHO, 1982; ZILBERMAN, 2012). O seu início é incerto, mas diversas culturas antigas trazem sua riqueza literária em manifestações orais transcritas em materiais rudimentares, como argila e pergaminhos que foram encontradas por historiadores (COELHO, 1982). Alguns desses achados remontam à Grécia antiga, perpassando pelas escrituras cristãs no século II d.C., chegando à literatura ocidental que transformou as lendas, mitos e narrativas adultas em contos fantasiosos e maravilhosos, como os textos de Esopo, Andersen, os irmãos Grimm e Perrault, em decorrência do aumento do consumo desse tipo de texto pelos pequenos leitores, as crianças, a partir do século XIX (ARIÈS, 1981; CRUZ, 1958; COELHO, 1982; LAJOLO; ZILBERMAN, 2007).

No Brasil o surgimento da literatura infantil se deu pela instituição da Imprensa Régia, no ano de 1808, com as adaptações da literatura europeia, que se caracterizam por um distanciamento social e linguístico da população da colônia (COSTA, 2009; LAJOLO; ZILBERMAN, 2007). Com o amadurecimento da consciência nacionalista brasileira seguida pela Proclamação da República e a intensa industrialização do país, houve uma grande fabricação de produtos para o público infantil, dentre eles, os livros. Essa modificação culminou em 1920 com o Modernismo, em seu movimento antropofágico, que reconstruiu a identidade nacional baseada nos movimentos culturais (COELHO, 1982; NUNES MEDEIROS, 2010).

O grande marco simbólico desse nacionalismo na literatura infantil brasileira literário: o cotidiano de uma população rural; o folclore nacional, retratando o 
brasileiro em sua linguagem, seu comportamento, sua relação com a natureza e suas questões sociais (CADERMATORI, 1991; COSTA, 2009; GREGORIN FILHO, 2009).

Monteiro Lobato rompeu o tradicionalismo que vigorava interessando-se pela literatura infantil a partir do nascimento de seus filhos. Ele se preocupava com o conteúdo da leitura que eles realizariam. Lobato respeitava o que era de fora, mas reconhecia a importância de que se conhecesse a cultura do país no qual viviam (COELHO, 1982). Em sua obra é possível observar a linguagem mais informal, principalmente nas falas dos personagens, bem como a associação de personagens da cultura mais eurocêntrica e os do nosso folclore, realizando uma aproximação de mundos nas aventuras que ele criava (LAJOLO; ZILBERMAN, 2007).

A ciência nas obras lobatianas se relaciona ao entendimento que esse autor trazia de que o desenvolvimento e a evolução da sociedade brasileira perpassavam pelo conhecimento científico. O autor procurava disseminar informações científicas da época com a finalidade de desencadear nos leitores deduções científicas por meio da imaginação e da fantasia, com a possibilidade de levá-los a uma aprendizagem científica por meios não convencionais (GROTO, 2014; SANTOS; SOUZA; FARIA, 2013).

Camenietzki (1988) reitera o papel da ciência nos acontecimentos que rondam as histórias do Sítio do Pica-Pau Amarelo. Sempre presente nessa obra, tratada com temas específicos ou com assuntos secundários, a ciência se apresenta de várias maneiras, ora como "saber inútil" ora como "saber útil" e, enfim, como "saber malversado", caracterizando os momentos históricos pelos quais transitava Monteiro Lobato.

Inicialmente o saber científico presente nas narrativas infantis de Lobato foi classificado como inútil e os cientistas transfiguravam-se em rabugentos personagens. O segundo momento da escrita lobatiana, incluindo o livro tratado nesta pesquisa - A reforma da natureza -, a visão da ciência e do cientista se opõe à primeira, uma vez que o saber científico é valorizado e suas narrativas estão repletas de concretizações. Já o último saber, o malversado, coincide com o final da vida do autor e suas decepções com a humanidade, com o registro de uma ciência distorcida pela sociedade, e o cientista torna a ser o rabugento da primeira fase (CAMENIETZKI, 1988).

Após esse movimento estrondoso de criatividade na literatura infantil, proporcionado por Monteiro Lobato, que estimulou o surgimento de diversos novos autores, houve um declínio desse tipo de produção em decorrência do surgimento da televisão e da associação pedagógica e paradidática da literatura infantil que a tornou, para alguns pesquisadores, como um recurso artístico de menor importância (COELHO, 1982; LAJOLO; ZILBERMAN, 2007).

Monteiro Lobato, percebendo o lucro que a associação literatura-escola estava trazendo, por meio da associação pedagógica, inseriu no mercado seu paradidático Narizinho Arrebitado. E o sucesso desse empreendimento se deveu não somente à ousadia do autor, mas principalmente pela leitura fácil e imaginativa que seu texto trazia aos pequenos leitores (ABREU, BARROS, 2004).

Contudo, o viés pedagógico da literatura infantil não a minimiza enquanto fazer artístico, uma vez que seu caráter instrucional, associado à alfabetização; e 
o seu caráter artístico, associado à fantasia e ao maravilhoso, são indissociáveis desde o seu surgimento (COELHO, 1982; LAJOLO; ZILBERMAN, 2007). Cruz (1958) ressalta ainda que o enovelamento da emoção, da intelectualidade e da cultura de uma sociedade garante a sua expressão enquanto arte.

Essa indissociação entre arte e pedagogia, que foi verificada na literatura infantil, é relacionada ao caráter próprio da leitura que engloba o ato de ler propriamente dito e o encadeamento das ideias. $\mathrm{O}$ ato de ler pauta-se pela decodificação dos signos linguísticos que coopta a pedagogia. O encadeamento de ideias exibe a abstração de que a leitura proporciona moderada pela vivência individual, assim como nas leituras anteriormente realizadas (GREGORIN FILHO, 2009; SILVA, 1998). Paulo Freire (2005) chamava essa vivência individual de "leitura de mundo", o que dá à literatura infantil um sentido amplificador, porque se torna uma leitura argumentativa e discursiva, repleta de afetividade e emoção que desencadeia a formação do leitor reflexivo (GIRALDELLI; ALMEIDA, 2008; GREGORIN FILHO, 2009; SEMEN, 2012).

Essa "leitura de mundo" é legitimada pelo ensino de Ciências a partir da compreensão do ambiente natural, tecnológico e social (AMORIN; BORGES, 2014). Esse conhecimento científico, compreendido de forma lúdica pela literatura, aproxima o leitor da ciência e da apreensão dos acontecimentos da natureza (ANTLOGA; SLONGO, 2012). A aproximação da ciência à literatura infantil pode permitir que o aprendizado se realize de forma mais motivadora e diferenciada. Isso por que a literatura pode ser o início para um processo de aprendizagem, tendo a pesquisa e a criação como bases para o seu desenvolvimento, por aguçar a curiosidade das crianças (AMORIN; BORGES, 2014; SANTOS; PIASSI, 2010; SANTOS; SOUZA; FARIA, 2013).

Assim como Monteiro Lobato, Antloga e Slongo (2012) afirmam que a ciência é capaz de formar cidadãos conscientes e críticos. Associando a ciência à literatura infantil é possível compactuar para a abertura de espaços para o questionamento da sociedade aliados às interações interpessoais, promovendo o desenvolvimento de processos mentais superiores a partir de um objeto mediador - o livro (GIRALDELLI; ALMEIDA, 2008).

O livro, como objeto mediador, é uma ferramenta externa ao sujeito que pode proporcionar o aumento da sua capacidade de ação e memorização, promovendo a internalização que constitui a abstração por meio da representação mental da realidade (MINCK, 2002; OLIVEIRA, 1993). O livro e a história que ele contém podem ser um grande mediador que transforma os processos mentais, se estabelecendo como amplificadores culturais, pois medeiam a ação humana já que agem como ferramentas psicológicas (CARVALHO, 2015).

Segundo Oliveira (1993), a internalização origina os processos psicológicos essenciais que diferenciam a aprendizagem humana, processo esse que não ocorre sem o suporte fornecido pelo meio e por outras pessoas. O livro de literatura infantil pode ser esse suporte e, portanto, um amplificador cultural se utilizado como recurso de ensino e aprendizagem (FERRARI; MAESTRELLI; SCHOROEDER, 2010).

Oliveira (1993) traz ainda outro conceito de Vygotsky que são os níveis de desenvolvimento: potencial, real e proximal. 0 primeiro refere-se àquelas pessoas que necessitam de algum tipo de auxílio para realizar uma tarefa. O nível 
de desenvolvimento real é aquele que abarca sujeitos que estão com o conhecimento consolidado e que realizam a tarefa sem auxílio. O desenvolvimento proximal refere-se ao percurso que levará o sujeito de um extremo ao outro e esse percurso pode levar a mudanças no funcionamento intermental, por meio de intervenções, a fim de atingir o funcionamento intramental (TULVISTE; WERTSCH, 2002).

Dessa forma, defendemos que o ensino de Ciências pode estimular esse movimento de desenvolvimento intelectual, fornecendo subsídios para a sua ocorrência, baseando-se nos conhecimentos prévios das crianças desenvolvimento real - aumentando o nível de exigência. Essas exigências podem perpassar pela alfabetização aliada ao letramento que a ciência pode promover, como também favorecer o diálogo entre um conhecimento científico e um texto literário, estimulando a reflexão e a criticidade (DELIZOICOV; LORENZETTI, 2001). Assim é que foram propostas atividades com os textos de Monteiro Lobato para verificar a sua contribuição em um processo de ensino e aprendizagem de alunos do Ensino Fundamental I.

\section{METODOLOGIA}

Essa pesquisa sobre o processo de ensino e aprendizagem de alunos dos anos iniciais do Ensino Fundamental I a partir de atividades com textos de literatura infantil examinou os preceitos de uma pesquisa qualitativa, cujos dados foram submetidos a uma análise microgenética (BRANCO; KELMAN, 2004; GOÉS, 2000). Este tipo de pesquisa valoriza o contato direto do pesquisador com o ambiente de estudo.

Godoy (1995) afirma que, em uma pesquisa qualitativa, a descrição dos fatos, o ambiente e as pessoas que participam da atividade devem ser analisados de maneira holística, considerando as relações interpessoais e das pessoas com o meio. A análise microgenética enfatiza a observação da construção dos dados partindo da valorização da cultura, história e semiótica no estudo do funcionamento humano. Nesse trabalho essa observação direcionada auxiliou na avaliação das comunicações durante a oficina, principalmente na relação alunoaluno e aluno-professor.

Foi escolhida uma turma do 3ㅇan ano do Ensino Fundamental I por ser a etapa de consolidação da alfabetização bem como o início do contato das crianças com os conceitos científicos. Foram selecionadas, aleatoriamente, 21 crianças das turmas dessa série de uma escola de uma cidade de Minas Gerais. Houve necessidade de uma seleção, uma vez que muitas crianças queriam fazer parte da oficina e o espaço oferecido pela escola era pequeno. A oficina foi aplicada pela própria pesquisadora, em face da relutância das docentes da escola, que alegaram não ter preparo para desenvolver as atividades propostas.

A escola é ampla e dividida em dois pavilhões que abrigam, separadamente, a Educação Infantil e Ensino Fundamental I do Ensino Fundamental II. Cada um desses pavilhões apresenta dois andares que abrigam turmas nos três turnos. São atendidos alunos de toda a cidade bem como moradores de um distrito pertencente a outro município. As famílias atendidas são consideradas de classe 
algum tipo de necessidade especial, que estavam distribuídas em diferentes turmas da escola.

A atividade proposta foi uma oficina de leitura, estabelecendo com os participantes um diálogo sobre os objetivos da oficina e procurando ouvir deles as suas expectativas e sugestões (MORAIS, 2011). Para essa oficina, foram selecionados alguns textos do livro "Reforma da Natureza", de Monteiro Lobato, que é dividido em duas fases: a primeira aborda as aventuras da boneca Emília e sua amiga Rã, durante a ausência de Dona Benta e demais personagens do Sítio do Pica-Pau Amarelo; a segunda fase trata do retorno desses personagens, dando destaque às aventuras científicas da boneca e do Visconde de Sabugosa.

O livro apresenta dezenove capítulos que retratam a vida no campo, sendo o pano de fundo a valorização do conhecimento científico do personagem Visconde (GROTO; MARTINS, 2015). Desses capítulos foram selecionados dez que atendiam de maneira mais satisfatória a demanda dos conteúdos abordados nos anos iniciais do ensino fundamental I (QUADRO 1).

Quadro 1 - Relação entre capítulos do livro e PCN (1997)/BNCC(2018)

\begin{tabular}{|c|c|c|c|}
\hline $\begin{array}{l}\text { Número } \\
\text { do } \\
\text { capítulo }\end{array}$ & Nome do capítulo & PCN/Ciências & BNCC \\
\hline 3 & O passarinho-ninho & \multirow{5}{*}{ Ambiente } & \multirow{2}{*}{$\begin{array}{c}\text { Ambiente, } \\
\text { recursos e } \\
\text { responsabilidades }\end{array}$} \\
\hline 4 & A reforma da mocha & & \\
\hline 5 & Borboletas, moscas e formigas & & \multirow{3}{*}{$\begin{array}{c}\text { Vida: constituição } \\
\text { e evolução }\end{array}$} \\
\hline 6 & Reformas na Europa e nas pulgas & & \\
\hline 7 & Os odres vivos e o peso & & \\
\hline 8 & O livro comestível & \multirow{5}{*}{$\begin{array}{l}\text { Ser humano e } \\
\text { saúde }\end{array}$} & \multirow{5}{*}{$\begin{array}{c}\text { Sentidos, } \\
\text { percepção e } \\
\text { interações }\end{array}$} \\
\hline 12 & O laboratório do visconde & & \\
\hline 13 & Os estudos & & \\
\hline 14 & A pulga gigantesca & & \\
\hline 15 & A noventaequatropeia & & \\
\hline
\end{tabular}

Fonte: Autoria própria (2019).

Um segundo filtro foi realizado selecionando dois textos: "Borboletas, moscas e formigas" e "A reforma da Mocha" para compor as atividades da oficina (QUADRO 2). Esses dois textos foram indicados por trazer, em sua temática, relação com os conteúdos de ciências que já haviam sido abordados em sala pelas professoras regentes e que poderiam ser evocados pelas crianças no decorrer da leitura. A oficina foi subdividida em "momentos" com o intuito de melhor organizar as atividades que seriam realizadas. 
Quadro 2 - Organização dos momentos da oficina

\begin{tabular}{|c|c|c|c|}
\hline Momento & $\begin{array}{l}\text { Tema do } \\
\text { momento }\end{array}$ & Duração & Tema e conceitos das aulas \\
\hline $\begin{array}{l}\text { Momento } \\
1\end{array}$ & $\begin{array}{l}\text { Tem Ciência } \\
\text { em tudo que } \\
\text { eu vejo? }\end{array}$ & $\begin{array}{l}50 \\
\text { minutos }\end{array}$ & $\begin{array}{l}\text { Definição de Ciências. } \\
\text { Local para se aprender Ciências. } \\
\text { Onde é possível encontrar os conceitos de } \\
\text { Ciências no nosso cotidiano. }\end{array}$ \\
\hline $\begin{array}{l}\text { Momento } \\
2\end{array}$ & $\begin{array}{l}\text { Sensibilização: } \\
\text { "A reforma da } \\
\text { natureza" }\end{array}$ & $\begin{array}{l}50 \\
\text { minutos }\end{array}$ & $\begin{array}{l}\text { Apresentação do livro (capa, contracapa, } \\
\text { título, imagens iniciais). } \\
\text { Iniciar contextualizando a história sem } \\
\text { leitura. } \\
\text { Apresentação da proposta de trabalho }\end{array}$ \\
\hline $\begin{array}{l}\text { Momento } \\
3\end{array}$ & $\begin{array}{l}\text { Borboletas, } \\
\text { moscas e } \\
\text { formigas }\end{array}$ & $\begin{array}{l}50 \\
\text { minutos }\end{array}$ & $\begin{array}{l}\text { Bichinhos de jardim } \\
\text { Invertebrados }\end{array}$ \\
\hline $\begin{array}{l}\text { Momento } \\
4\end{array}$ & $\begin{array}{c}\text { Reforma da } \\
\text { Mocha }\end{array}$ & $\begin{array}{c}50 \\
\text { minutos }\end{array}$ & $\begin{array}{c}\text { Anatomia vegetal } \\
\text { Relações ecológicas }\end{array}$ \\
\hline $\begin{array}{l}\text { Momento } \\
5 \\
\end{array}$ & $\begin{array}{l}\text { O que você já } \\
\text { sabe? }\end{array}$ & $\begin{array}{c}50 \\
\text { minutos }\end{array}$ & $\begin{array}{c}\text { Desenhos e frases relativas ao que já } \\
\text { sabem sobre ciências }\end{array}$ \\
\hline
\end{tabular}

Fonte: Autoria própria (2019).

No primeiro dia foram realizados dois momentos da oficina (momento 1 e 2). No momento 1 ocorreu uma sensibilização das crianças utilizando imagens do cotidiano, como uma mulher lavando roupa, pessoas cozinhando, filmes e desenhos animados. Com esse momento, procurou-se perceber o olhar que elas lançam sobre a ciência e onde elas identificam que é possível a sua ocorrência. Já no momento 2, foi feita uma narrativa simples da Segunda Guerra Mundial, utilizando também imagens com o intuito de contextualizar a história que iríamos começar a pesquisar. A necessidade dessa "contação" deveu-se ao fato de o livro trazer um recorte de um evento histórico, que não se estuda neste ciclo de alfabetização.

No segundo dia, momento 3 , teve início o trabalho das crianças como pesquisadoras. Esse trabalho foi estimulado antes do início da leitura, motivandoas a buscar indícios da presença da ciência no texto da maneira como elas haviam feito com as imagens. Seguiu-se a leitura do texto "Borboletas, moscas e formigas". As crianças ouviram a narrativa, que tratava de assuntos relativos aos invertebrados, bichinhos de jardim que são assuntos abordados nos primeiros anos de escolarização. Após a leitura, abriu-se um espaço para debate de ideias contidas no texto para verificar se houve compreensão. Seguiu-se uma discussão que visou à investigação a respeito dos conteúdos de ciências existentes no texto e se eles foram identificados pelas crianças.

No terceiro dia, a proposta feita foi a atividade sugerida como momento 4 . As crianças dispunham do texto que seria trabalhado para que pudessem acompanhar a leitura feita pela pesquisadora. Posteriormente realizou-se uma investigação sobre o que cada criança considerava como pertencente à ciência no texto, riscando palavras ou frases que remetessem a essa ideia. Realizou-se o recorte desses trechos grifados que foram colados em uma folha, tendo sido solicitado que as crianças escrevessem o porquê de terem considerado esse recorte como fazendo parte da ciência. Esperava-se, com essa atividade, que as crianças recordassem algum conteúdo de ciências trabalhado em sala de aula. 
No último dia da oficina, a atividade proposta abordava os conhecimentos científicos que foram consolidados até o 3 o ano. Esse foi o momento 5 da oficina. Foram distribuídas folhas para que participantes representassem, por meio de desenhos ou frases, o que elas recordavam sobre as matérias de ciências que estudaram.

Os dados foram coletados utilizando filmagens, gravações de áudios e caderno de campo. No diário de campo foram anotados as impressões e sentimentos percebidos durante a aplicação da oficina. As gravações foram transcritas e posteriormente analisadas juntamente com as filmagens. Os turnos de fala que enfatizaram o envolvimento emocional e o lúdico, e que demonstraram a literatura como amplificadora cultural para o ensino de Ciências, foram selecionados.

A pesquisa foi submetida ao Comitê de Ética da Universidade Federal de Ouro Preto, que deliberou positivamente pela liberação do trabalho de campo. As oficinas ocorreram uma vez por semana, totalizando cinco encontros, com duração máxima de cinquenta minutos cada. As leituras ocorreram de diferentes maneiras: inicialmente foi feita apenas pela pesquisadora; posteriormente as crianças puderam, além de ouvir, acompanhar a leitura em textos individuais. Os textos de Monteiro Lobato foram suporte para que as crianças pudessem externar os conteúdos de ciências que já haviam aprendido em sala de aula com as professoras regentes, utilizando a ludicidade e a fantasia que a literatura infantil proporciona.

\section{RESULTADO E DISCUSSÃO}

Nesta seção serão apresentados alguns turnos de fala recortados das transcrições dos momentos da oficina. Eles foram escolhidos para destacar o papel da literatura infantil no ensino de ciências como amplificador cultural. Nomeamos turnos os trechos das transcrições selecionados para a análise, devido à maior prevalência das falas para a pesquisa, porque permitiram também o entendimento das mediações proporcionadas pelo livro como uma ferramenta didática para o ensino de ciências nos anos iniciais do Ensino Fundamental I.

Durante a sensibilização realizada no momento 1 , quando as crianças foram estimuladas a investigar sobre a presença da ciência nas imagens que lhes eram apresentadas, ficou evidente o interesse delas, que são identificadas por pseudônimos, no trabalho de investigação. Todos queriam apontar onde estavam vendo ciência nas imagens que lhes eram apresentadas.

Pesquisadora: Terceiro ano, atenção aqui em mim só um instante. Têm ciências em lavar roupa, têm ciências comer, têm ciências no cinema, no desenho animado.

Jorge: Na pintura.

Pesquisadora: Têm ciências no filme, têm ciências nas artes, têm ciências na brincadeira, eu quero descobrir se aqui oh. $\mathrm{O}$ que que é isso aqui?

Todos: Os livros,

Amanda: Tia, aí tem muita ciências. 
Roberto: Vai que tem um livro de ciências aí.

Pesquisadora: Será que só se tiver um livro de ciências aqui vai ter ciências?

Ana: Não.

Nesse primeiro momento as crianças estavam ansiosas para falar, contudo, detinham seus apontamentos às plantas, animais e ao meio ambiente. Um comportamento já observado em outras pesquisas que apresentam que crianças e jovens em idade escolar trazem a ideia de ciência relacionada aos conteúdos que estão sendo abordados em sala de aula e a projetos que envolvem o meio ambiente (BONFIM, 2015).

As imagens utilizadas nessa "contação" se revelaram excelentes amplificadores culturais pelo grande envolvimento emocional e pela inter-relação entre as crianças já que elas se manifestaram o tempo todo. Foi perceptível também o envolvimento emocional com a estimulação da abstração, auxiliando, assim, no entendimento do fato histórico narrado, ou seja, a emoção influenciou a compreensão e esse é um ponto importante para o ensino e aprendizagem de ciência (FRANCISCO JÚNIOR; GARCIA JÚNIOR, 2010). Essa questão pode ser observada nesse turno de fala no qual as crianças demonstraram seus sentimentos por expressões de nojo, de surpresa, de piedade e de comemoração pela derrota do "mal":

Pesquisadora: Presta atenção nessa história que eu vou contar pra vocês pra vocês entenderem o começo do livro que a gente vai trabalhar, ok?

Essa pessoa aqui, ela se chama, se chamava Adolf Hitler.

Roberto: Ãn, Adolfo Hitler.

Pesquisadora: Ele era alemão.

Roberto: Adolfo Hitler.

Pesquisadora: Vamos, atenção aqui. Esse sujeito liderou a Alemanha numa guerra que matou um monte de gente.

Ana: Mais de sete mil.

(...)

Jorge: Eco, eca.

Pesquisadora: Era assim, umas 100 pessoas por dia. Crianças, eles pegavam as crianças e levavam para os laboratórios e fazia experiência para tentar mudar a cor do olho da criança.

Matheus: Nó!

Pesquisadora: Pegava tinta de caneta. E a criança sem tá anestesiada nem nada. Pegava tinta de caneta, colocava em uma seringa e enfiava no olho da criança.

Joana: Eca!

Alice: Ai!

Roberto: Credo, tia, não fala isso não!

Pesquisadora: Ele era uma pessoa do bem?

Todos: Não!!

Pesquisadora: E aí, ele desencadeou uma guerra porque o mundo inteiro ficou contra ele, falou assim: você é muito malvado, nós vamos destruir você. E essa guerra ficou conhecida como Segunda Guerra Mundial

Jorge: Inha! 
Pesquisadora: E aí a Alemanha perdeu, e perdeu feio!

Roberto: Ele já perdeu?

Pesquisadora: Exatamente, ele perdeu.

Ana: E morreu?

Jorge: Uhuu!!

Pesquisadora: E ele morreu na guerra.

Roberto: Bem feito, ficou fazendo maldade com as pessoas.

Durante o momento 2, no qual ocorreu a "contação" para a contextualização da história, foram utilizadas imagens contendo elementos históricos do primeiro capítulo, para ilustração. Esse procedimento garantiu um maior envolvimento dos participantes, evidenciando, assim, como as imagens podem se tornar um poderoso suporte para a compreensão, chegando a superar o texto verbal (ANTLOGA; SLONGO, 2012).

À medida que a leitura era aprofundada, tornava-se perceptível o envolvimento e o interesse das crianças pelas travessuras de Emília e Rãzinha. 0 turno de fala a seguir, selecionado do momento 3 , ilustra esse encantamento:

Pesquisadora: (leitura do livro) Emília esqueceu a vaca e saiu correndo atrás da borboleta, ela grita: "dessa não tenho ainda!". Mas não conseguiu pegála; cansadinha da corrida. Explicou:

- Estou fazendo uma bela coleção de borboletas e dessas azuis não consigo. São das mais ariscas. Temos também de reformar as borboletas.

- Impossível Emília! - gritou a Rã - Tudo nelas é tão benfeito, tão direitinho e lindo, que qualquer reforma as estraga.

- Minha reforma das borboletas - explicou Emília - não é na beleza delas, e sim no gênio delas. Quero que se tornem "pegáveis", como os besouros. Já reparou que besouro não foge da gente

Rogério: Não!

Pesquisadora: Mansíssimos. Mas as borboletas, sobretudo destas azuis, são umas pestes de tão ariscas.

Todos: Risos

Pesquisadora: Quando descubro uma sentada e me aproximo, ela "bota-se pra fora"!

E as borboletas azuis foram reformadas, ficando mansinhas como besouros. - E as moscas? - perguntou a Rã. - As moscas - respondeu Emília - vão ficar sem asas,

Ana: Nó!

Roberto: Nó que doido!

O envolvimento emocional com as travessuras da boneca Emília e sua amiga Rãzinha foi perceptível pelas reações que as crianças demonstravam no decorrer da história, em face dos elementos lúdicos trazidos pelo texto, que causaram encantamento e inquietação, transformando-se em memória (AMORIM E BORGES, 2014). Semen (2012) destaca que o lúdico presente na literatura infantil é importante para o aprendizado das crianças, principalmente se ocorre a interação entre esse e a ciência. Essa relação torna-se um amplificador cultural porque promove a compreensão dos conceitos da ciência, estabelecendo uma relação dialógica entre os pares (ANTLOGA; SLONGO, 2012). 
Dessa forma, esse amplificador cultural possibilita inúmeras inter-relações de conhecimentos distintos (FILIPE, 2012). É possível afirmar que o lúdico da literatura infantil subsidia uma mediação entre ensino e aprendizagem dentro da ciência (ALMEIDA; GIRALDELLI, 2008). E isso é trazido por turnos de fala do momento 3 que demonstram as discussões sobre o texto "Borboletas, moscas e formigas":

Pesquisadora: Isso aqui é ciências, terceiro ano?

Todas: É!

Pesquisadora: Por quê?

Tainara: Sim, porque a gente é detetive.

Pesquisadora: Sim, vocês são detetives, e aí?

Carlos: Que, pra modificar, a gente precisa de ciências.

Pesquisadora: Ah! Olha o que o Carlos me disse, que, pra modificar a gente precisa de ciências. Olha aqui, presta atenção. Tem uma hora lá que a Emília disse que estudou bem o caso e ela achou que as formigas eram...

Todos: Perfeitas.

Pesquisadora: Perfeitas! Então, vocês acham que o Monteiro Lobato, na hora que ele escreveu esse livro, ele conhecia bem as formigas?

Todos: Sim!

Pesquisadora: Onde que ele aprendeu sobre as formigas?

Roberto: Na escola.

Tainara: Nas ciências.

Outro ponto que é encontrado na literatura infantil é o fantástico que se materializa no imaginário do leitor (COELHO, 1982). O fantástico carrega as aspirações humanas estimulando, dessa maneira, a compreensão dos fatos reais utilizando suas narrativas. Assim, é possível afirmar que o fantástico presente na literatura infantil pode ser um mediador dos processos reflexivos e argumentativos, atuando na zona de desenvolvimento proximal. Tal estímulo foi percebido no turno de fala durante o momento 4:

Pesquisadora: Peguem um lápis de escrever. Quem não tem lápis de escrever levanta a mão, só levanta a mão, não precisa falar nada. Me conta uma coisa, o que vocês acharam dessa reforma da Emília e da Rã?

Ana: Meio esquisita!

Pesquisadora: Meio esquisita por quê?

Ana: Os chifres "ficou" com bolinhas nas pontas, daí a Mocha não vai conseguir se defender se alguém atacar ela.

Pesquisadora: Ah! Se ela for atacada, ela fica indefesa, né? Alguém tem mais alguma coisa "pra" me falar? O que que achou dessa reforma?

Camila: Ela colocou o rabo da Mocha nas costas pra ela poder abanar as moscas todas.

Pesquisadora: Você achou essa ideia boa?

Camila: Não.

Pesquisadora: Por quê?

Página | 196

Camila: A vaca não gostou parece.

Pesquisadora: A vaca ficou com cara de que não gostou, você acha? 


\author{
Camila: Sim. \\ Pesquisadora: Pode falar, Daiane. \\ Daiane: Eu achei a ideia da torneirinha nas tetas legal. \\ Pesquisadora: Você gostou da ideia da torneirinha? \\ Luis: Eu não gostei não! \\ Pesquisadora: É? Por que você não gostou, Luís? \\ Luis: Por que não. \\ Ana: Parece que ela sofreu uma mutação animal!
}

Tal mediação proposta pela literatura infantil que evidenciou a fantasia, a reflexão e a argumentação ocorrem pelo encontro entre o conceito espontâneo e o conceito científico proposto por Vygotsky. O conceito espontâneo é fruto das vivências habituais da criança pela associação que ela faz entre o conceito (definição) e o objeto. Já o conceito científico tem sua origem nas atividades mediadas e estruturadas de aprendizagem, promovendo uma associação racional e abstrata entre conceitos de maneira ordenada e mediada (LIMA, MAUÉS, 2006).

Lima e Maués (2006) afirmam que essa mediação precisa ser ordenada para que a criança incorpore os conceitos científicos, levando em consideração aqueles que ela já conhece, pois esses são a base para o seu desenvolvimento. A partir de um trabalho estruturado, ocorre uma ressignificação de entendimentos ao longo de um processo de escolarização da criança. Desse modo, é necessário que esse procedimento, que se refere à aprendizagem de conceitos científicos, seja estabelecido já nas séries iniciais do ensino fundamental I para fomentar a mediação do desenvolvimento dos processos mentais superiores, aliados também à alfabetização e ao letramento das crianças nesta etapa escolar (RODRIGUES, RODRIGUES, 2018).

Em se tratando do tema da pesquisa, essa construção de processos mentais superiores pode ter sido estimulada também pelo texto de Monteiro Lobato, porque, em alguns turnos de fala, foi perceptível a abstração que as crianças faziam em alguns trechos da história que as levou a uma compreensão considerável dos conteúdos trazidos para a discussão (BARONE; PORCACHIA, 2011). Desse modo, por meio dessa pesquisa, foi percebido que, para as atividades do ensino de ciências, o texto de Monteiro Lobato atua na zona de desenvolvimento proximal, podendo alcançar o nível de desenvolvimento real, sendo seus textos, dessa forma, um grande instrumento de mediação desse processo (OLIVEIRA, 1993).

\title{
CONSIDERAÇÕES FINAIS
}

A literatura traz as características da sociedade e os livros disseminam conhecimento entre os leitores, desde os primeiros impressos, aumentando a formação desse público, em especial para o ensino e aprendizagem de Ciências. A literatura traduz com o lúdico e o imaginário o saber científico, atuando como um mediador (ALMEIDA; GIRALDELLI, 2008; ANTLOGA; SLONGO, 2012; CRUZ, 1958; GREGORIN FILHO, 2009; SEMEN, 2012; ZILBERMAN, 2012). 
Outros autores abordam esse trabalho mediador como instrumentos que realizam no processo formativo do sujeito (BARROS, 2009; MINICK; TULVISTE; WERTSCH 2002; OLIVEIRA, 1993), ratificando a importância da imaginação para o aprendizado de ciências (GREGORIN FILHO, 2009).

Assim, esta pesquisa procurou descrever e avaliar o caráter mediador da literatura infantil no ensino de ciências no 1ㅇ ciclo do Ensino Fundamental I, buscando compreender a possibilidade de seu uso como um amplificador cultural capaz de estimular o desenvolvimento dos processos mentais superiores.

A oficina demonstrou que ocorreram várias interações entre as crianças e os textos lidos, comprovando que a literatura foi um efetivo instrumento de mediação entre o meio externo e os processos de desenvolvimento dessas crianças. Como um mediador, ela possibilita a compreensão de mundo utilizando a abstração seguida da externalização do pensamento que é compartilhado com a turma. Essa ocorrência pôde ser percebida nas diversas situações de demonstração de vários sentimentos que o texto proporcionava às crianças. A externalização de sentimentos permitiu a avaliação de que as crianças se manifestaram pelo lúdico e pela imaginação presentes na obra e que, muitas vezes, tais sentimentos e reações ocorreram em confronto aos fatos reais.

Esse confronto permitiu o entendimento da ocorrência de internalização das informações, ou seja, as crianças demonstraram o aparecimento do desenvolvimento de processos mentais superiores. Foram perceptíveis a mediação e as reflexões ocasionadas pelos textos, podendo, assim, afirmar que eles funcionaram como amplificadores culturais. A reflexão é fundamental para a aquisição de conceitos científicos que necessitam de abstração e imaginação daquele que aprende.

Dessa maneira, pode ser percebido que a literatura infantil é capaz de despertar o interesse nas crianças por possibilitar a abstração e a imaginação, sendo, por esse motivo, um mediador importante para a aprendizagem em ciências. Isso por que a literatura proporciona a interação com a história, o envolvimento emocional e a reflexão sobre os eventos fantasiosos que ela traz.

Finalmente, pode-se concluir que o ensino de Ciências com aporte da literatura infantil é capaz de ser um grande instrumento para os professores das séries iniciais, contribuindo não somente com a alfabetização e o enriquecimento do repertório das crianças, mas, também, possibilitando outra visão da ciência que pode transcender a sala da aula. 


\title{
Science teaching in the early years with the support of Monteiro Lobato child literature
}

\begin{abstract}
Children's literature is a textual genre that has a playful, attractive and imaginative character and is therefore widely used by teachers of the early years of elementary school to help children acquire reading skills, which provides enrichment of vocabulary. This support can be widely and unrestrictedly used in various subjects, such as in classes dealing with content related to the natural sciences. Thus, this paper aims to describe and analyze the process of teaching and learning science in the early grades of elementary school provided by an activity that used children's literature to work scientific content. This research had as subjects students from a public school in a city in the interior of Minas Gerais who were enrolled in the third year of elementary school and used short stories from Monteiro Lobato for the development of the activity. The speech shifts were separated in order to demonstrate by microgenetic analysis the changes in speech that demonstrate the playfulness, creativity and imagination mobilized by the stories and that were important to evidence evidence of science learning. This characteristic of arousing the imagination of literary products is conducive to the learning of science that in many contents requires abstraction to understand natural phenomena. It is noteworthy that Monteiro Lobato's work proved to be an important tool, as it was a cultural amplifier that allowed the construction of meanings by children. This activity was designed for the early years of elementary school but could be adapted to other levels of education.
\end{abstract}

KEYWORDS: Scientific Literacy. Children's literature. Science teaching. Elementary School. 


\section{REFERÊNCIAS}

ABREU, T. M. C. e S. N. de; Barros, L. de H. Um Lobato educador: sob o prisma da fecundidade da obra infantil lobatiana. 2004. Dissertação (Mestrado). Programa de Pós-Graduação em Letras, Universidade Federal de Pernambuco, Recife, 2004.

AMORIM, K. P. L; BORGES, C. S. O valor da literatura infantil no ensino de Ciências. In: FÓRUM INTERNACIONAL DE PEDAGOGIA. Agosto, 2014, Santa Maria. Anais do VI FIPED. Santa Maria: Associação Internacional de Pesquisa na Graduação em Pedagogia (AINPGP), 2014

ANTLOGA, D. C; SLONGO, I. I. P. Ensino de ciências e Literatura Infantil: uma articulação possível e necessária. Seminário de Pesquisa em Educação da Região Sul, 9․, 2012, Caxias do Sul.

ARIÈS, P. História social da criança e da família. Trad. Dora Flaksman. 2a edição. Rio de Janeiro: Zahar Editores, 1981. p.279

BONFIM, M. A. A. A visão de alunos do ensino fundamental sobre ciência e tecnologia: um estudo de caso sobre a contribuição da Semana Nacional de C\&T. Dissertação (Mestrado), Centro Federal de Educação Tecnológica Celso Suckow da Fonseca, 2015.

BRASIL. Parâmetros curriculares nacionais: ciências naturais 3o e 4 ciclos. Secretaria de Educação Fundamental, Brasília: MEC/SEF, 1998.

BRASIL. Base nacional comum curricular: proposta preliminar. Secretaria de Educação Básica, Brasília, MEC/SEB, 2a versão, 2016.

CADEMARTORI, L. O que é literatura infantil. São Paulo, Brasiliense, 1991.

CAMENIETZKI, C. Z. O saber imponente: estudo da noção de ciência na obra infantil de Monteiro Lobato. 1988. Dissertação de Mestrado - FGV, Rio de Janeiro.

CARVALHO, R. C. de S. Análise de uma proposta de sequência didática: puberdade e adolescência como temas para o estudo da sexualidade. Minas Gerais. 2015. 124f. Dissertação (Mestrado Profissional em Ensino de Ciências) Instituto de Ciências Exatas e Biológicas, Universidade Federal de Ouro Preto.

COELHO, N. N. A literatura infantil: história, teoria, análise (das origens orientais ao Brasil de hoje). 2 ed. São Paulo, Quiron/Global, 1982.

COSTA, M. M. Literatura infantil. 2 ed. Curitiba, IESDE Brasil, 2009, 236 p.

CRUZ, J. M. História da Literatura. 8a ed. São Paulo, Melhoramentos, 1958. 595 p.

DEL PRETTE, Z. A. P. DELL PRETTE, A. Notas sobre pensamento e linguagem de Skinner e Vygotsky. Porto Alegre, Psicologia: Reflexão e Crítica, 1995, v.8, n.1, p. 147-164. 
FILIPE, R. I. B. da S. A Promoção do Ensino das Ciências Através da Literatura Infantil. Dissertação de Mestrado em educação: Área de especialização em didática das ciências, Universidade de Lisboa, 2012, 203 p.

FREIRE, P. A importância do ato de ler. São Paulo, Cortez, 2005.

GERKEN, C. H. de S. Cultura oral, escrita e cognição na psicologia de Jerome Bruner: dos amplificadores culturais aos modos narrativos e proposicionais. 25 Reunião Anual da ANPED, Caxambu, 2002.

GIRALDELLI, C. G. C. M.; ALMEIDA, M. J. P. M. de. Leitura coletiva de um texto de literatura infantil no Ensino fundamental: algumas mediações pensando o Ensino de Ciências. Ensaio Pesquisa em Educação em Ciências, vol. 10, n. 1, 2008, p 119.

GODOY, A. S. Introdução à pesquisa qualitativa e suas possibilidades. Revista de administração de empresas, São Paulo, 1995, v. 35, n.2 p. 57-63. Disponível em: http://www.scielo.br/pdf/rae/v35n2/a08v35n2.pdf

GÓES, M. C. R. A abordagem microgenética na matriz histórico-cultural: uma perspectiva par ao estudo da constituição da subjetividade. Cadernos CEDES, ano XX, n. 50, abril, 2000.

GREGORIN FILHO, J. N. Literatura infantil: múltiplas linguagens na formação de leitores. São Paulo, Melhoramentos, 2009, 128p.

GROTO, S. R. Ciência com Monteiro Lobato. Ciência hoje online. Out, 2014.

GROTO, S. R. MARTINS, André Ferrer Pinto. Monteiro Lobato em aulas de ciências: aproximando ciência e literatura na educação científica. Ciência e Educação. v. 21, n.1, p. 219-238, 2015.

FRANCISCO JÚNIOR, W. E.; GARCIA JÚNIOR, O. Leitura em sala de aula: um caso envolvendo o funcionamento da Ciência. Química nova escola. Vol. 32, n. 3, agosto, 2010, 191-199 p.

KELMAN, C. A. BRANCO, A. U. Análise microgenética em pesquisa com alunos surdos. Revista brasileira de educação especial, Marília, jan-abr, 2004, v.10, n. 1, p. 93-106.

LAJOLO, M.; ZILBERMAN, R. Literatura infantil brasileira: história e histórias. 6 ed. São Paulo, Ática, 2007.

LIMA, M. E. C. de C.; MAUÉS, E. Uma releitura do papel da professora das séries iniciais no desenvolvimento e aprendizagem de ciências das crianças. Belo Horizonte, Ensaio, 2006, v. 8, n. 2, p. 184-198.

LOBATO, M. A reforma da natureza. 2 ed. São Paulo, Globo, 2010.

LORENZETTI, L.; DEIZOICOV, D. Alfabetização científica no contexto das séries 
http://www.portal.fae.ufmg.br/seer/index.php/ensaio/article/view/35/66 Acesso em: 24 ago. 2015.

MINICK, N. O desenvolvimento do pensamento de Vygotsky. In: HARRY, Daniels. Uma introdução a Vygotsky. Trad. Marcos Bagno. Loyola, São Paulo, 2002.

MORAIS, M. de A. F. Oficina de leitura: vírus I. Repositório aberto. Universidade do Porto. Disponível em: https://repositorio-

aberto.up.pt/bitstream/10216/57301/2/44496.pdf

OLIVEIRA, M. K. Vygotsky: aprendizado e desenvolvimento - um processo sóciohistórico. São Paulo, Scipione, 1993.

PORCACCHIA, S. S.; BARONE, L. M. C. Construindo leitores. Estudos de Psicologia, Campinas, v. 28, n. 3, p. 395-402, jul-set, 2011. Disponível em:

http://www.scielo.br/pdf/estpsi/v28n3/a12v28n3.pdf.

RODRIGUES, C. S. C.; RODRIGUES, M, A. Refletindo sobre o ensino de ciências com professores dos anos iniciais por meio de uma sequência de ensino investigativo. Curitiba, ACTIO, 2018, v. 3, n.2, p. 58-79.

SABINO, M. M. do C. de. Importância educacional da leitura e estratégias para a sua promoção. Revista ibero-americana de educação. n. 45, mar, 2008. Disponível em: file://C:/Users/Usuario/Downloads/2398Sabino\%20(2).pdf.

SANTOS, F. R.; PIASSI, L. P. de C. O caso da borboleta Atíria: ensinando Ciências com literatura infanto-juvenil. Simpósio Nacional de Ensino de Ciência e Tecnologia, 2ㅇ, 2010, Paraná.

SANTOS, T. P.; SOUZA, A. R.; FARIA, F. P. Concepções de ciências nas obras de Monteiro Lobato: mapeamento e análise de termos científicos no livro Serões de Dona Benta. Ata do IX Encontro Nacional de Pesquisa em Educação em Ciências. Águas de Lindóia, Nov., 2013.

SCHROEDER, E. A; FERRARI, N; MAESTRELLI, S.R.P. Construção dos Conceitos Científicos em Aulas de Ciências: a teoria histórico-cultural do desenvolvimento como referencial para análise de um processo de ensino sobre sexualidade humana. Alexandria: Revista de Educação em Ciência e Tecnologia, v. 3, n. 1, p. 21-49, maio 2010.

SASSERON, L. H. CARVALHO, A. M. P. Alfabetização científica: uma revisão bibliográfica. Investigação em Ensino de Ciências. V.16, 2011. Disponível em: http://www.if.ufrgs.br/ienci/artigos/Artigo_ID254/v16_n1_a2011.pdf. Acesso em: 24 ago. 2015.

SEMEN, É. F. A Literatura Infantil como recurso metodológico para o ensino de ciências nos anos iniciais. Simpósio em Educação em Ciências da Amazônia, 2ํ, 2012, Manaus. 
WERTSCH, J. V.; TULVISTE, P. L. S. Vygotsky e a psicologia evolutiva contemporânea. In: Uma introdução a Vygotsky. Org. Harry Daniels, Trad. Marcos Bagno, São Paulo, Loyola, 2002.

ZILBERMAN, R. Teoria da literatura I. Curitiba, IESD, 2012, 208 p.

Recebido: 03 ago. 2019

Aprovado: 28 out. 2019

DOI: $10.3895 /$ actio.v4n3.10448

Como citar:

LANA, M. M. P. C.; SILVA, F. A. R. O ensino de ciências nos anos iniciais com o aporte da literatura infantil de Monteiro Lobato. ACTIO, Curitiba, v. 4, n. 3, p. 185-203, set./dez. 2019. Disponível em:

$<$ https://periodicos.utfpr.edu.br/actio>. Acesso em: XXX

Correspondência:

Márcia Priscilla Castro Lana

Rua José Carlos Gomes, 175, Vila Operária, Ouro Preto, Minas Gerais, Brasil.

Direito autoral: Este artigo está licenciado sob os termos da Licença Creative Commons-Atribuição 4.0

Internacional.

(c) 